\title{
Aging Affects Dopaminergic Neural Mechanisms of Cognitive Flexibility
}

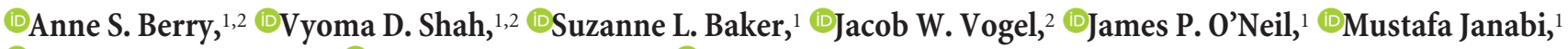

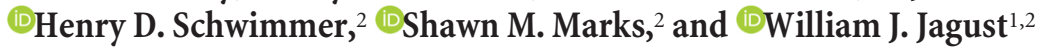 \\ ${ }^{1}$ Lawrence Berkeley National Laboratory, Berkeley, California 94720, and ${ }^{2}$ Helen Wills Neuroscience Institute, University of California Berkeley, Berkeley, \\ California 94720
}

Aging is accompanied by profound changes in the brain's dopamine system that affect cognitive function. Evidence of powerful individual differences in cognitive aging has sharpened focus on identifying biological factors underlying relative preservation versus vulnerability to decline. Dopamine represents a key target in these efforts. Alterations of dopamine receptors and dopamine synthesis are seen in aging, with receptors generally showing reduction and synthesis demonstrating increases. Using the PET tracer $6-\left[{ }^{18} \mathrm{~F}\right] \mathrm{fluoro}-\mathrm{L}-m-$ tyrosine, we found strong support for upregulated striatal dopamine synthesis capacity in healthy older adult humans free of amyloid pathology, relative to young people. We next used fMRI to define the functional impact of elevated synthesis capacity on cognitive flexibility, a core component of executive function. We found clear evidence in young adults that low levels of synthesis capacity were suboptimal, associated with diminished cognitive flexibility and altered frontoparietal activation relative to young adults with highest synthesis values. Critically, these relationships between dopamine, performance, and activation were transformed in older adults with higher synthesis capacity. Variability in synthesis capacity was related to intrinsic frontoparietal functional connectivity across groups, suggesting that striatal dopamine synthesis influences the tuning of networks underlying cognitive flexibility. Together, these findings define striatal dopamine's association with cognitive flexibility and its neural underpinnings in young adults, and reveal the alteration in dopamine-related neural processes in aging.

Key words: aging; cognitive flexibility; dopamine; fMRI; PET; task switching

\section{Significance Statement}

Few studies have combined measurement of brain dopamine with examination of the neural basis of cognition in youth and aging to delineate the underlying mechanisms of these associations. Combining in vivo PET imaging of dopamine synthesis capacity, fMRI, and a sensitive measure of cognitive flexibility, we reveal three core findings. First, we find evidence supporting older adults' capacity to upregulate dopamine synthesis. Second, we define relationships between dopamine, cognition, and frontoparietal activity in young adults indicating high levels of synthesis capacity are optimal. Third, we demonstrate alteration of these relationships in older adults, suggesting neurochemical modulation of cognitive flexibility changes with age.

\section{Introduction}

Healthy aging is associated with prominent declines in multiple components of the brain's dopamine system, which have been linked to disrupted cognition (Wang et al., 1998; Bäckman et al.,

Received Feb. 25, 2016; revised Sept. 27, 2016; accepted 0ct. 22, 2016.

Author contributions: A.S.B. and W.J.J. designed research; A.S.B., V.D.S., J.W.V., and H.D.S. performed research; S.L.B., J.P.O., and M.J. contributed unpublished reagents/analytic tools; A.S.B., V.D.S., and S.M.M. analyzed data; A.S.B. and W.J.J. wrote the paper.

This work was supported by National Institutes of Health Grants AG044292 and AG047686. We thank the reviewers for valuable comments that greatly benefited this manuscript.

The authors declare no competing financial interests.

Correspondence should be addressed to Dr. Anne S. Berry, Helen Wills Neuroscience Institute, University of California Berkeley, Berkeley, CA 94720. E-mail: aberry@lbl.gov.

DOI:10.1523/JNEUROSCI.0626-16.2016

Copyright $\odot 2016$ the authors $\quad 0270-6474 / 16 / 3612559-11 \$ 15.00 / 0$
2000; Mozley et al., 2001; Erixon-Lindroth et al., 2005). Even in healthy young adults, individual differences in dopamine profoundly influence executive functions, including cognitive flexibility (Cools et al., 2008; Stelzel et al., 2010; Samanez-Larkin et al., 2013). Dopamine therefore represents a prime target for investigating the neurochemical basis of variability in executive function in youth, and may represent a driver of powerful individual differences in cognitive aging. However, these relationships are rarely studied directly in humans because of difficulty assessing endogenous dopamine function. The present study measured dopamine synthesis capacity with the PET tracer 6- $\left[{ }^{18} \mathrm{~F}\right]$ fluoro-L- $m$ tyrosine (FMT), and examined its relationship with age, cognitive flexibility, and frontoparietal activation during an fMRI study of task switching. 
Task switching, an experimental paradigm requiring the rapid adjustment of behavior according to changing task rules, is a well-known measure of cognitive flexibility that is sensitive to brain dopamine (e.g., Samanez-Larkin et al., 2013). Previous task switching studies implicate dorsal striatum and specifically dorsal caudate nucleus (DCA) (for review, see Klanker et al., 2013), which receives rich dopaminergic input, and is highly connected with cortex via established cortico-striato-thalamo-cortical loops (Alexander et al., 1986). fMRI has further specified a role of lateral prefrontal cortex approximating BA 44/9, and posterior parietal cortex approximating BA 7 in task switching (Braver et al., 2003). Linking dopamine, task switching, fMRI activation, a $\mathrm{D}_{2}$ receptor polymorphism that elevates receptor density is associated with both increased switch costs and prefrontal inefficiency measured as higher BOLD activation relative to controls (Stelzel et al., 2010).

Although multiple components of the dopamine system decline in older adults, including loss of dopamine producing neurons in the substantia nigra (Fearnley and Lees, 1991), and reduced receptor and transporter density (Seeman et al., 1987; Volkow et al., 1994; Frey et al., 1996; Ishibashi et al., 2009), parallel decline in dopamine synthesis is not evident. Indeed, there is evidence that synthesis may be higher in older adults relative to young. FMT studies in humans and nonhuman primates show age-related increases in synthesis capacity (DeJesus et al., 2001; Braskie et al., 2008) in line with findings from postmortem tissue (Kish et al., 1995). However, little is known about the impact of upregulated synthesis on cognitive performance and underlying neural activity, although it has been linked to working memory disruption (Klostermann et al., 2012; but see Landau et al., 2009).

Cognitive flexibility is acutely sensitive to dopaminergic function as revealed by endogenous PET and pharmacological measures (Samanez-Larkin et al., 2013), with subtle augmentation having sometimes dramatic effects on cognitive function. The inverted-U-shaped model describes dopamine's influence on cognition, which proposes that shifts above or below an "optimal" dopamine tipping-point disrupt performance (for review of the inverted-U-shaped model of dopamine, see Cools and Robbins, 2004; Cools and D'Esposito, 2011). Although to date the majority of support for this model is derived from pharmacological studies, it may be possible to observe quadratic effects for in vivo dopamine measures using an individual differences approach. Invoking the inverted-U model, Dreher et al. (2008) reported that aging shifts relationships between dopamine and reward-related neural activity, as the positive correlation between dopamine synthesis capacity and prefrontal activation observed in young people became negative in older adults. However, the behavioral relevance of this switch is unclear, as activation was collected independent of a performance measure.

Here, we examined relationships between age, dopamine synthesis capacity, fMRI, and behavioral measures of task switching. We examined whether DCA dopamine's influence on cognition and neural function was described by quadratic, inverted-Ushaped relationships across all participants. Next, we tested the hypothesis that the higher levels of dopamine synthesis capacity observed in older adults would transform relationships between DCA dopamine and task switching, revealing the effect of aging on dopaminergic neural mechanisms of cognitive flexibility.

\section{Materials and Methods}

Participants. Fifteen older adults (70-83 years old; 9 female) and 21 young adults (20-31 years old; 10 female) participated in FMT PET and MRI sessions and are included in the present report (Table 1). Older
Table 1. Demographics and task switching performance ${ }^{a}$

\begin{tabular}{|c|c|c|c|c|}
\hline & Young & Older & $t$ test & $\begin{array}{l}\text { Effect size } \\
\text { (Cohen's d) }\end{array}$ \\
\hline \multirow[t]{2}{*}{ Age (years) } & 23.80 & 77.43 & & \\
\hline & $(2.59)$ & $(3.87)$ & & \\
\hline \multirow[t]{2}{*}{ Education (years) } & 15.57 & 17.07 & $t=2.47$ & 0.80 \\
\hline & $(1.32)$ & $(2.31)$ & $p<0.05$ & \\
\hline \multirow[t]{2}{*}{ Episodic memory } & 1.65 & -0.04 & $t=5.83$ & 2.05 \\
\hline & $(0.85)$ & $(0.80)$ & $p<0.001$ & \\
\hline \multirow[t]{2}{*}{ Working memory } & 0.70 & -0.48 & $t=4.22$ & 1.49 \\
\hline & $(0.88)$ & $(0.69)$ & $p<0.001$ & \\
\hline \multirow[t]{2}{*}{ Processing speed } & 2.01 & -0.35 & $t=11.19$ & 3.87 \\
\hline & $(0.59)$ & $(0.63)$ & $p<0.001$ & \\
\hline \multirow[t]{2}{*}{ Task repeat RT } & 902.37 & 1079.07 & $t=3.54$ & 1.25 \\
\hline & (175.99) & $(94.05)$ & $p=0.001$ & \\
\hline \multirow[t]{2}{*}{ Task switch RT } & 979.71 & 1167.50 & $t=3.71$ & 1.29 \\
\hline & $(167.09)$ & $(120.60)$ & $p<0.001$ & \\
\hline \multirow[t]{2}{*}{ Single task RT } & 649.94 & 738.22 & $t=3.10$ & 1.07 \\
\hline & $(94.34)$ & $(67.83)$ & $p<0.005$ & \\
\hline \multirow[t]{2}{*}{ Switch cost (\% RT) } & 9.42 & 8.25 & $t<1$ & 0.15 \\
\hline & $(8.59)$ & $(7.02)$ & $p>0.05$ & \\
\hline \multirow[t]{2}{*}{ Task repeat accuracy } & 0.89 & 0.81 & $t=2.40$ & 0.83 \\
\hline & $(0.08)$ & $(0.11)$ & $p<0.05$ & \\
\hline \multirow[t]{2}{*}{ Task switch accuracy } & 0.88 & 0.79 & $t=2.77$ & 0.88 \\
\hline & $(0.08)$ & $(0.12)$ & $p<0.01$ & \\
\hline \multirow[t]{2}{*}{ Single task accuracy } & 0.94 & 0.95 & $t<1$ & 0.16 \\
\hline & $(0.07)$ & $(0.05)$ & $p>0.05$ & \\
\hline
\end{tabular}

${ }^{a}$ Data are mean (SD). Older adults' task switching performance was slower and less accurate relative to that of younger adults, but there was no group difference in RT switch cost measured as percentage change for task switch trials relative to task repeat.

adults were recruited from the Berkeley Aging Cohort Study, and young adults were recruited via fliers. The study was approved by the Institutional Review Boards at the University of California, Berkeley and Lawrence Berkeley National Laboratory. All participants provided written consent, and received monetary compensation for participating in the study.

Participants had normal or corrected to normal vision, did not take medication affecting cognition, and had no neurological or psychological conditions. Older adults were characterized as cognitively normal using an interview and test battery, including several subtests of the Wechsler Adult Intelligence Scale-Revised (Wechsler, 1987), and the Mini Mental State Exam (Folstein et al., 1975). Older adults scored at least 25 on the Mini Mental State Exam (range: 25-30; mean \pm SD, $28.33 \pm 1.59$ ), and were screened for current depression using the Geriatric Depression Scale (range: $0-8$; mean \pm SD, $3.36 \pm 2.76$ ) (Yesavage et al., 1982). Data for an additional older adult and young adult were excluded from the present analysis due to sleeping during the fMRI task and structural abnormality.

Older adults previously underwent Pittsburg compound B ([ $\left.\left.{ }^{11} \mathrm{C}\right] \mathrm{PIB}\right)$ PET imaging under a different protocol. Distribution volume ratios were low (range 0.91-1.09; mean \pm SD, $1.00 \pm 0.04$ ) with 14 of 15 PIB negative (Villeneuve et al., 2015).

Neuropsychological examination: cognitive factor score. Neuropsychological factor scores for episodic memory, working memory, and executive function/processing speed were generated for each participant using a maximum likelihood analysis (Bentler and Kano, 1990) standardized by test results from a larger sample of 346 Berkeley Aging Cohort Study participants as described previously (Schöll et al., 2016) (Table 1). Briefly, 14 cognitive tests met criteria for factor score generation as they were normally distributed but not excessively collinear $(r<0.7)$, and allowed for minimal data loss (data present for $>90 \%$ of total sample). The final solution (three factors) showed significant goodness-of-fit $\left(\chi^{2}=67.85, \mathrm{df}=42, p<0.01\right.$, RMSEA $\left.<0.05\right)$ explaining $56 \%$ of total model variance. Factor 1 was interpreted as episodic memory and was comprised of the California Verbal Learning Test (Delis et al., 2000), WMS-III Logical Memory Story $(\mathrm{A}+\mathrm{B} 1)$ and Visual Reproduction (Wechsler, 1987), Listening Span (Daneman and Carpenter, 1980), and 
Category Fluency (Spreen and Benton, 1977). Factor 2 was interpreted as working memory and was comprised of WMS-II Digit Span (forward and backward), and Arithmetic tasks (Wechsler, 1987). Factor 3 was interpreted as processing speed/executive function and was composed of the Digit-Symbol test (Smith, 1982), Stroop (Stroop, 1938), WMS-III Mental Control test (Wechsler, 1987), Trails A, and taps per second on a finger tapping task (Reitan and Wolfson, 1985). Factor scores were generated by $z$-scoring each variable and, for each participant, multiplying by the MLE-derived weight specific to that variable for each factor. Factor scores for three young adults could not be generated due to incomplete neuropsychological battery data.

PET data acquisition. The present study used the FMT PET tracer to measure dopamine synthesis capacity. Similar to $6-\left[{ }^{18} \mathrm{~F}\right]$ fluorodopa (FDOPA), FMT is a substrate for aromatic amino acid decarboxylase, an enzyme in the dopamine synthesis pathway. Although not the rate-limiting step in synthesis, its activity provides an estimate of dopamine synthesis capacity when provided with enough substrate (DeJesus, 2003). FDOPA's signal, unlike FMT's, is affected by catechol-O-methytransferase (DeJesus, 2003), decreasing signal-to-noise. FMT is oxidized to $6-\left[{ }^{18} \mathrm{~F}\right]$ fluorohydroxyphenylacetic acid, and its signal is trapped in the presynaptic terminal, unlike FDOPA, which is subject to postrelease processing.

FMT was synthesized at Lawrence Berkeley National Laboratory using methods previously described (VanBrocklin et al., 2004). Participants ingested $2.5 \mathrm{mg} / \mathrm{kg}$ of carbdopa $\sim 1 \mathrm{~h}$ before scanning to minimize the peripheral metabolism of FMT. Data were acquired using a Biograph Truepoint 6 PET/CT (Siemens Medical Systems). After a short CT scan, participants were injected with $\sim 2.5 \mathrm{mCi}$ of FMT as a bolus in an antecubital vein. Dynamic acquisition frames were obtained over $90 \mathrm{~min}$ in 3 D mode ( 25 frames total: $5 \times 1 \mathrm{~min}, 3 \times 2 \mathrm{~min}, 3 \times 3 \mathrm{~min}, 14 \times 5 \mathrm{~min}$ ). Data were reconstructed using an ordered subset expectation maximization algorithm with weighted attenuation, corrected for scatter, and smoothed with a $4 \mathrm{~mm}$ FWHM kernel.

Structural MRI data acquisition and processing. Images were acquired on a 1.5T Magnetom Avanto System (Siemens Medical Systems) with a 12-channel head coil. Each participant was scanned using a T1-weighted MPRAGE protocol $\left(\mathrm{TR}=2110 \mathrm{~ms}\right.$; $\mathrm{TE}=3.58 \mathrm{~ms} ; \mathrm{FA}=15^{\circ}$; matrix $=$ $256 \times 256 ; \mathrm{FOV}=256$; sagittal plane; voxel size $=1 \times 1 \times 1 \mathrm{~mm} ; 160$ slices). MPRAGE scans were segmented using FreeSurfer version 5.1 (http://surfer.nmr.mgh.harvard.edu/). Cerebellar gray matter was used as the reference region in FMT PET analyses because this region shows very little tracer uptake. The most anterior $1 / 4$ of cerebellar gray was removed from the reference region to limit contamination of signal from the substantia nigra and ventral tegmental area. PET analyses focused on dopamine synthesis capacity measured in regions of interest (ROIs) in striatum. DCA, dorsal putamen (DPUT), and ventral striatum (VST) ROIs were manually drawn on each participant's MPRAGE as previously described (Mawlawi et al., 2001) using Mango software (http:// ric.uthscsa.edu/mango/) (see Fig. 1a). Intrarater reliability was high for all regions. For ROIs of 5 participants drawn by 2 raters, the Sorensen-Dice coefficient ranged from 0.80 to 0.86 , and the intraclass correlation coefficient ranged from 0.95 to 0.99 .

PET data analysis. FMT PET data were preprocessed using SPM8 software (Friston et al., 2011). To correct for motion between frames, images were realigned to the middle (12th) frame. The first five images were summed before realignment. Structural images (including posterior cerebellar reference region and striatal ROIs) were coregistered to PET images using the mean image of frames corresponding to the first $20 \mathrm{~min}$ of acquisition as a target. Graphical analysis for irreversible tracer binding was performed using Patlak plotting (Patlak and Blasberg, 1985) with posterior cerebellar gray matter used as the reference region. $\mathrm{K}_{\mathrm{i}}$ images were generated from PET frames corresponding to 25-90 min, which represent the amount of tracer accumulated in the brain relative to the cerebellum. These images are comparable with $\mathrm{K}_{\mathrm{i}}$ images obtained using a blood input function but are scaled to the volume of tracer distribution in the reference region.

ROI-based partial volume correction was applied (Rousset et al., 1998) to generate the best approximation of FMT signal originating from DCA, DPUT, and VST, and to minimize differences in $\mathrm{K}_{\mathrm{i}}$ driven by age-related changes in gray matter, white matter, and CSF volume. To apply the partial volume correction in native space, we used FreeSurfer-generated ROIs for gray matter cortical and subcortical regions, white matter, and CSF with hand-drawn striatal ROIs substituting for the automated striatal segmentation.

$\mathrm{K}_{\mathrm{i}}$ and partial volume corrected $\mathrm{K}_{\mathrm{i}}$ data were submitted to repeatedmeasures ANOVA in SPSS version 23 (IBM) with factors region (DCA, DPUT, VST) and age group (young, older). Greenhouse-Geisser sphericity correction was applied as needed for reporting $p$ values, but degrees of freedom are reported as integers in the text for easier reading. Effect sizes for repeated-measures ANOVA are reported using $\eta_{\mathrm{G}}^{2}$ (Bakeman, 2005), which gives smaller values than the frequently used $\eta_{\mathrm{P}}^{2}$, but is preferable as it reduces error when comparing across studies (Fritz et al., 2012). Post hoc $t$ tests were conducted with effect sizes computed using Cohen's $d$ for between-subjects effects and $d z$ for within-subjects effects.

fMRI behavioral task and analysis. Participants performed a twocondition task switching experiment (see Fig. 2a). The task was generated using PsychoPy 1.80.06 (Peirce, 2007). On each trial, a cue (square or diamond) was presented for $300 \mathrm{~ms}$ after which a number between 1 and 9 was presented for $2000 \mathrm{~ms}$. For square cues, participants determined whether the number was odd (right button press) or even (left button press). For diamond cues, participants determined whether the number was $>5$ (right button press) or $<5$ (left button press). The number 5 was never presented. Participants were given $2000 \mathrm{~ms}$ to respond and were instructed to respond as quickly as possible without sacrificing accuracy. Fixation periods of duration 2000, 4000, or $6000 \mathrm{~ms}$ separated each trial. Responses were limited to two buttons, rather than 4 buttons, to introduce response overlap, which is thought to increase cognitive control demands (Meiran et al., 2000). Response hand and cue-rule mapping were counterbalanced across participant.

Participants performed 6 functional runs comprised of 48 trials each. Four runs contained both conditions while two runs contained just a single condition. For the two-condition runs, stimuli were pseudorandomized to ensure the same number stimulus was not presented two times in a row, the same cue was not presented more than four times in a row, consecutive right versus left hand responses did not repeat more than three times in a row, and there were no more than three consecutive rule repeat trials or rule switch trials. Participants performed out-ofscanner practice with and without trial-to-trial feedback, until they reached $60 \%$ accuracy. In the scanner, participants performed a brief practice to ensure they could see the stimuli.

The primary performance measure was response time (RT), although accuracy was also calculated. Analyses presented here focus on "switch cost," the difference in RT for task switch trials (correct responses preceded by correct responses for the different condition) versus task repeat trials (correct responses preceded by correct responses for the same condition). High switch costs, in this framework, reflect cognitive inflexibility. Switch cost was the primary measure because it has been linked reliably to dopamine function (e.g., Samanez-Larkin et al., 2013). However, age effects for switch cost are minimal relative to the large and consistent age effects found for "mixing cost," the difference in RT for task repeat trials in the two-condition runs versus RT for trials in the single condition run (Wasylyshyn et al., 2011).

RT and accuracy data were submitted to repeated-measures ANOVA with factors trial type (switch, repeat) and age group (young, older). Although we do not focus the present report on mixing cost, we include an additional repeated-measures ANOVA with factors trial type (repeat, single task) and age group (young, older) to confirm the current task switching paradigm replicates the broader literature.

Additionally, we evaluated the relationship between switch cost ( $\%$ change in RT for switch trials relative to repeat trials) and DCA FMT $\mathrm{K}_{\mathrm{i}}$. Influential models posit dopaminergic modulation of cognitive function is best described as an inverted-U (Cools and Robbins, 2004; Cools and D'Esposito, 2011). To test the applicability of this model, we applied linear, quadratic, and cubic polynomial fits to data describing the relationship between FMT $\mathrm{K}_{\mathrm{i}}$ and switch cost. Adjusted $r^{2}$ values are reported. To preview our results, we found that data were best described by a quadratic, U-shaped fit. As a test of the robustness of the quadratic fit, a permutation procedure was applied to assess the likelihood that our results could have occurred by chance. Briefly, residuals from the model 
without the quadratic term were randomly shuffled without replacement using the mrg33k3a pseudorandom number generator (L'Ecuyer, 1999) for 1000 permutations. For each new sample, regression was performed using the quadratic term as the independent variable. $p$ values indicate the likelihood that observed $t$ values for the quadratic term were greater than random associations generated from shuffled data. $p$ values from permutation testing are reported for all significant quadratic models.

To test whether the relationships between FMT $\mathrm{K}_{\mathrm{i}}$ and switch cost were significantly different between age group, the age $\times$ FMT $\mathrm{K}_{\mathrm{i}} \times$ switch cost interaction was tested. Follow-up analyses tested Pearson correlations for individual groups. Regression, interaction, and correlation analyses were conducted using R version 3.2.2 (http://www.R-project. org). Permutation testing was conducted using Python software version 2.7 (http://www.python.org).

fMRI data acquisition and preprocessing. Six functional task runs and resting state scans were collected in the same session as the T1 MPRAGE. The six functional task runs were acquired with at $\mathrm{T} 2^{\star}$-weighted EPI sequence $\left(\mathrm{TR}=2200 \mathrm{~ms}\right.$; $\mathrm{TE}=50$; flip angle $=50^{\circ}$; matrix $64 \times 64$; $\mathrm{FOV}=220 \mathrm{~mm}$; voxel size $=3.44 \times 3.44 \times 3.91 \mathrm{~mm}$ ). A total of 28 axial slices oriented to the AC-PC line were acquired in ascending order to give whole brain coverage. The resting state scan was acquired before task performance with a $\mathrm{T}^{*} \mathrm{EPI}$ sequence $(\mathrm{TR}=2200 \mathrm{~ms}$; $\mathrm{TE}=50$; flip angle $=90^{\circ}$; matrix $64 \times 64 ; \mathrm{FOV}=220 \mathrm{~mm}$; voxel size $=3.44 \times 3.44 \times$ $3.91 \mathrm{~mm}$ ). Twenty-eight axial slices were acquired in an interleaved order. The first 10 volumes acquired for each functional scan were discarded to allow for magnetization preparation and stabilization. In-plane turbo inversion recovery images $(\mathrm{TR}=2000 \mathrm{~ms}, \mathrm{TE}=11$, matrix $=$ $256 \times 256 ; \mathrm{FOV}=220$; voxel size $=0.43 \times 0.43 \times 3.91 \mathrm{~mm}, 28$ slices $)$ were collected as an intermediate target for registration of MPRAGE and EPI images.

fMRI data were analyzed using SPM12 software. Functional images were corrected for differences in slice timing and were realigned to the first volume to correct for head movement. To spatially normalize functional images to the MNI template, the in-plane and MPRAGE images were used as intermediates. Following normalization, functional images were smoothed with an $8 \mathrm{~mm}$ FWHM isotropic Gaussian kernel.

fMRI GLM. Data were analyzed using a multisession GLM implemented in SPM12 (Friston et al., 1995). Task switch (high-low rule, odd-even rule) and task repeat trials (high-low rule, odd-even rule) were modeled as separate predictors. All omissions, error responses, and trials following errors were modeled together as a single predictor and are not included in the present analysis. Predictors were time-locked to the onset of the number stimulus. To mitigate the effect of motion artifact, six motion regressors derived from individual subject realignment were included in the model. Additionally, a parametric regressor was created for individual trial RT to control for possible time-on-task effects on frontoparietal activation (Grinband et al., 2008). For each participant, we used a parametric regression approach to control for the effect of differences in mean RT on differences in brain activity between switch and repeat trials. Specifically, we created an index for each trial by subtracting the mean RT across all conditions and dividing by SD (Yarkoni et al., 2009).

A priori ROI analyses. fMRI studies consistently implicate lateral prefrontal and posterior parietal cortex in task switching. Given that these frontoparietal regions are thought to be engaged transiently to support rapid updating of task set during switch trials, we selected ROIs from a previous mixed blocked/event-related design study of task switching (Braver et al., 2003). Regions showing transient increases in activation during switch trials included left lateral prefrontal cortex approximating BA $44 / 9$ (MNI $-46,14,24)$ and left posterior parietal cortex approximating BA 7 (MNI $-28,-70,45)$, and have been closely replicated (Jimura and Braver, 2010). We tested whether increased activation for switch relative to repeat trials in these ROIs (average of $8 \mathrm{~mm}$ radius spheres centered on peak coordinates from Braver et al., 2003 converted from Talairach space) showed linear, quadratic, or cubic relationships with DCA FMT $\mathrm{K}_{\mathrm{i}}$ (averaged across left and right hemisphere), and conducted interaction analyses as described above. Control analyses were conducted using ROIs in right and left primary visual cortex $(8 \mathrm{~mm}$ spheres surrounding $\pm 28,-96,-6$; Anderson et al., 2011; Kiviniemi et al., 2009), and left and right primary motor cortex (8 $\mathrm{mm}$ spheres surrounding $\pm 37,-25,63$; Mayka et al., 2006) for which we hypothesized no relationship between DCA dopamine and activation, and no interaction with age group.

Exploratory whole-brain analyses. First, we examined whether there were age-related differences in activation between young and older adults using a voxelwise independent $t$ test on the switch $>$ repeat contrast.

Second, we identified regions significantly activated for the switch $>$ repeat contrast for all participants with age included as a covariate. We tested whether increased activation for switch relative to repeat trials in these regions showed a linear, quadratic, or cubic relationship with DCA FMT $K_{i}$, and conducted interaction analyses as described above. We first conducted analyses on all significantly activated regions, with complementary analyses limited to peaks in lateral prefrontal and posterior parietal cortex as these regions are strongly associated with task switching independent of stimulus type (Kimberg et al., 2000; Sohn et al., 2000; e.g., Dove et al., 2000).

For voxelwise significance testing, an initial cluster forming threshold of $p<0.001$ was applied, which is more conservative than the commonly used $p<0.01$ (Woo et al., 2014; Eklund et al., 2016). An additional minimum cluster extent threshold was applied using Monte Carlo simulation implemented in REST toolbox version 1.8 AlphaSim (www. restfmri.net/forum/; cluster-level threshold $p<0.05$ ) (Song et al., 2011). This principled extent-thresholding method accounts for spatial correlations of voxels and does not make assumptions about data distribution and smoothness.

Resting state functional connectivity analysis. Resting state scans were preprocessed as described above. Connectivity analyses were performed using the Functional Connectivity Toolbox version 14.p (CONN; www. nitrc.org/projects/conn) (Whitfield-Gabrieli and Nieto-Castanon, 2012) in SPM12. Anatomical images were segmented into gray matter, white matter and CSF to create masks for signal extractions. Regressors of no interest included motion, white matter, and CSF. Data underwent linear detrending and were bandpass filtered $(0.008-0.09 \mathrm{~Hz})$.

We created four functional connectivity maps for each participant using seeds identified in the univariate analysis in right and left inferior frontal gyrus ( $8 \mathrm{~mm}$ spheres surrounding MNI: $54,6,10 ;-54,14,18$ ) and right and left precuneus ( $8 \mathrm{~mm}$ spheres surrounding MNI: $12,-68$, $52 ;-12,-68,48)$. The four seed-to-voxel maps were averaged to create a composite frontoparietal connectivity map for each subject. Connectivity values were extracted from bilateral DCA and tested for relationships with DCA FMT $\mathrm{K}_{\mathrm{i}}$ as described above. Parallel control analyses were conducted for connectivity values extracted from right and left primary visual cortex ( $8 \mathrm{~mm}$ spheres surrounding MNI: \pm 28 , $-96,-6)$ and primary motor cortex $(8 \mathrm{~mm}$ spheres surrounding MNI: $\pm 37,-25,63)$.

\section{Results}

\section{PET}

Older adults had elevated FMT $\mathrm{K}_{\mathrm{i}}$ relative to young adults (Fig. $1 b)$. Repeated-measures ANOVA showed a main effect of age $\left(F_{(1,34)}=18.94, p<0.001, \eta_{\mathrm{G}}^{2}=0.24\right)$, a main effect of region $\left(F_{(2,68)}=154.45, p<0.001, \eta_{\mathrm{G}}^{2}=0.58\right)$, and a region $\times$ age interaction $\left(F_{(2,68)}=3.96, p=0.03, \eta_{\mathrm{G}}^{2}=0.04\right)$. Post hoc analyses determined the region $\times$ age interaction was driven by most elevated signal in DCA for older adults relative to young $\left(t_{(34)}=\right.$ 5.07, $p<0.001, d=1.68$; independent $t$ test), compared with $\operatorname{DPUT}\left(t_{(34)}=2.77, p=0.009, d=0.93\right)$ and $\operatorname{VST}\left(t_{(34)}=1.98\right.$, $p=0.056, d=0.68)$.

Although we use partial volume corrected FMT $\mathrm{K}_{\mathrm{i}}$ as our primary measure, noncorrected data showed a similar pattern of results. There was a main effect of age $\left(F_{(1,34)}=19.36, p<0.001\right.$, $\left.\eta_{\mathrm{G}}^{2}=0.26\right)$, a main effect of region $\left(F_{(2,68)}=224.75, p<0.001\right.$, $\left.\eta_{\mathrm{G}}^{2}=0.62\right)$, but the region $\times$ age interaction was not significant $\left(F_{(2,68)}<1\right)$. 

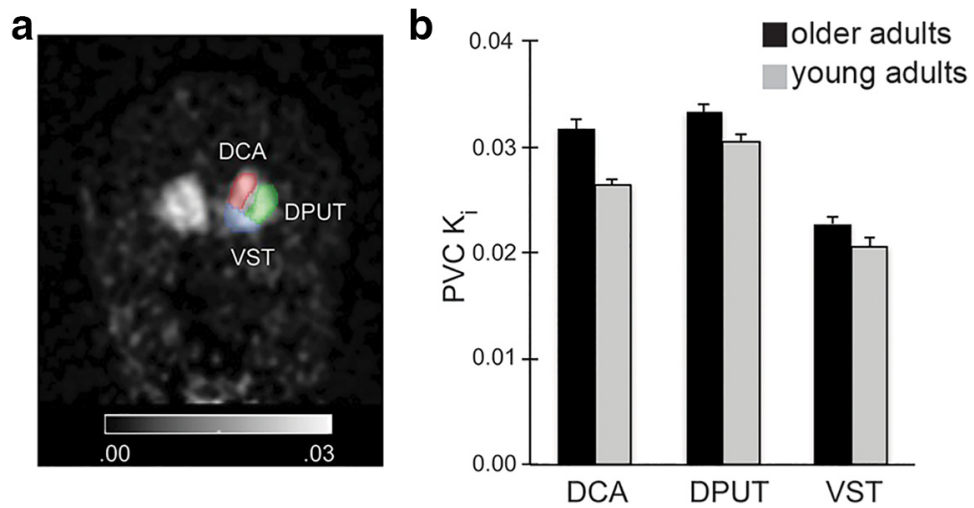

Figure 1. FMT signal is elevated in older adults relative to young. $\boldsymbol{a}$, ROIs in bilateral DCA, DPUT, and VST were drawn on each participant's structural scan and were coregistered with FMT $K_{i}$ images. Above are one participant's ROIs overlaid on $K_{i}$ image. The scale reflects $K_{\mathrm{i}}$ values. $\boldsymbol{b}$, Dopamine synthesis capacity was elevated in older adults relative to young $\left(F_{(1,34)}=18.94, p<0.001\right)$. Partial volume corrected $(P V C) K_{i}$ values are displayed. Data are mean \pm SEM.

\section{fMRI behavior}

Analyses focused on the comparison of task repeat and task switch trials in the two-condition runs. Task performance generally replicated previous findings (Table 1). Both groups showed robust and equivalent effects of task switching evidenced by main effect of trial type $\left(F_{(1,34)}=40.13, p<0.001, \eta_{\mathrm{G}}^{2}=0.05\right)$ and no trial $\times$ age interaction $\left(F_{(1,34)}<1\right)$. Older adults were slower than young adults overall $\left(F_{(1,34)}=14.06, p=0.001, \eta_{\mathrm{G}}^{2}=0.28\right)$.

Accuracy data showed a similar pattern. Accuracies were lower for task switch trials relative to task repeat trials, at trend level $\left(F_{(1,34)}=3.62, p=0.07, \eta_{\mathrm{G}}^{2}=0.004\right)$. There was no trial type $\times$ age interaction $\left(F_{(1,34)}=1.41, p=0.24\right)$, although older adults were less accurate overall $\left(F_{(1,34)}=7.07, p=0.01\right.$, $\left.\eta_{\mathrm{G}}^{2}=0.17\right)$.

To confirm the present task was sensitive to effects reported in the broader literature, we conducted additional repeatedmeasures ANOVAs to detect age differences in global switch cost. Participants were slower and less accurate for task repeat trials relative to single task trials (main effect of task RT: $F_{(1,34)}=$ $330.30, p<0.001, \eta_{\mathrm{G}}^{2}=0.54$; accuracy: $F_{(1,34)}=35.49, p<0.001$, $\left.\eta_{\mathrm{G}}^{2}=0.25\right)$. Older adults were slower but not less accurate than young adults overall (RT: $F_{(1,34)}=12.77, p=0.001, \eta_{\mathrm{G}}^{2}=0.23$; accuracy: $\left.F_{(1,34)}=2.69, p=0.11, \eta_{\mathrm{G}}^{2}=0.04\right)$, and there was an age $\times$ task interaction (RT: $F_{(1,34)}=7.59, p<0.01, \eta_{\mathrm{G}}^{2}=0.03$; accuracy: $\left.F_{(1,34)}=6.50, p=0.02, \eta_{\mathrm{G}}^{2}=0.06\right)$, indicating larger increases in RT and deceases in accuracy for repeat trials in older adults.

\section{Association between FMT and switch cost}

We submitted data to linear, quadratic, and cubic regression models testing the relationship between DCA FMT $\mathrm{K}_{\mathrm{i}}$ and switch cost. Combining groups, the linear relationship was not significant $\left(r^{2}=0.03, F_{(1,34)}=2.10, p=0.16\right)$, although quadratic $\left(r^{2}=0.36, F_{(2,33)}=10.89, p<0.0005\right)$ and cubic were $\left(r^{2}=0.37\right.$, $\left.F_{(3,32)}=7.98, p<0.0005\right)$. Comparative testing across models confirmed the quadratic fit outperformed the linear $\left(F_{(1,33)}=\right.$ $18.59, p=0.0001)$, and cubic fit did not explain more variance than quadratic $\left(F_{(1,32)}=1.54, p=0.22\right)$. Permutation testing confirmed the stability of the quadratic effect $(p=0.001 ; 1000$ permutations).

Considering young and older adults separately, ANOVA revealed an interaction between age, DCA FMT $\mathrm{K}_{\mathrm{i}}$, and switch cost, indicating that these relationships differed as a function of age group $\left(F_{(1,32)}=9.03, p=0.005\right)$ (Fig. $\left.2 b\right)$. High synthesis ap- peared optimal for young adults (Pearson's $r=-0.61, p=0.003)$ as greater synthesis capacity was associated with increased flexibility. However, at the higher synthesis seen in older adults, this relationship was not evident $(r=0.24$, $p=0.39)$.

\section{fMRI a priori ROI analyses}

There was no age-related difference in frontoparietal activation in ROIs in left lateral prefrontal cortex $(8 \mathrm{~mm}$ sphere surrounding MNI $-46,14,24)$ and posterior parietal cortex $(8 \mathrm{~mm}$ sphere surrounding $\mathrm{MNI}-28,-70,45)$ defined by Braver et al. (2003) (average both ROIs, $\left.t_{(34)}<1\right)$. The effect of DCA FMT $\mathrm{K}_{\mathrm{i}}$ on frontoparietal activation was tested in linear, quadratic, and cubic regression models. Across groups there was no linear relationship between DCA FMT $\mathrm{K}_{\mathrm{i}}$ and averaged frontoparietal activation $\left(F_{(1,34)}<1\right)$, although there was a significant quadratic $\left(r^{2}=0.26, F_{(2,33)}=7.29\right.$, $p=0.002)$ and cubic relationship $\left(r^{2}=0.24, F_{(3,32)}=4.73, p=\right.$ $0.007)$. The quadratic fit outperformed the linear $\left(F_{(1,33)}=13.27\right.$, $p=0.0009)$, with no significant improvement with the cubic fit $\left(F_{(1,32)}<1\right)$. Permutation testing confirmed the stability of the quadratic effect ( $p=0.001 ; 1000$ permutations).

Considering young and older adults separately, ANOVA revealed an interaction between age, DCA FMT K $\mathrm{K}_{\mathrm{i}}$, and activation, indicating these relationships differed as a function of age group $\left(F_{(1,32)}=11.22, p=0.002\right.$; Fig. $\left.3 a\right)$. This interaction remained significant after controlling for performance $\left(F_{(1,31)}=8.50, p=\right.$ 0.006). Closely mirroring dopamine effects observed for behavioral switch cost, young adults showed tight coupling between DCA FMT $K_{\mathrm{i}}$ and activation $(r=-0.61, p=0.003)$, with no significant relationship at the higher synthesis levels in older adults $(r=0.38, p=0.16)$.

We performed a parallel analysis using ROIs in primary visual and motor cortex where we did not hypothesize a relationship between DCA FMT $\mathrm{K}_{\mathrm{i}}$ and activation nor an interaction with age group. There was no age-related difference in primary visual activation $\left(t_{(34)}<1\right)$. Linear, quadratic, and cubic fits were not significant (all $F$ values $<1.67, p>0.20$ ), and there was no age group $\times$ DCA FMT $\mathrm{K}_{\mathrm{i}} \times$ activation interaction $\left(F_{(1,32)}<1\right.$; Fig. $3 c)$. Similarly for motor cortex, there was no age-related difference in primary motor activation $\left(t_{(34)}<1\right)$. Linear, quadratic, and cubic relationships were not significant (all $F$ values $<1$ ), and there was no age group $\times$ DCA FMT $\mathrm{K}_{\mathrm{i}} \times$ activation interaction $\left(F_{(1,32)}<1\right)$. As a further test of the anatomical specificity of the significant interaction effects reported for a priori frontoparietal ROIs, ANOVA probed the interaction between age group, DCA FMT $\mathrm{K}_{\mathrm{i}}$, activation, and region. The four-way interaction was significant for both primary visual $\left(F_{(1,64)}=4.61, p=0.04\right)$ and primary motor cortex $\left(F_{(1,64)}=4.01, p=0.05\right)$.

\section{fMRI exploratory analyses}

Voxelwise analyses, including all participants, identified a number of frontoparietal regions with significantly greater activation for task switch trials relative to task repeat trials (Fig. 4; Table 2), although no regions showed significantly greater activation for the opposite contrast. Likewise, there were no significant voxelwise age group differences in activation for either contrast as assessed by independent $t$ tests. 
a

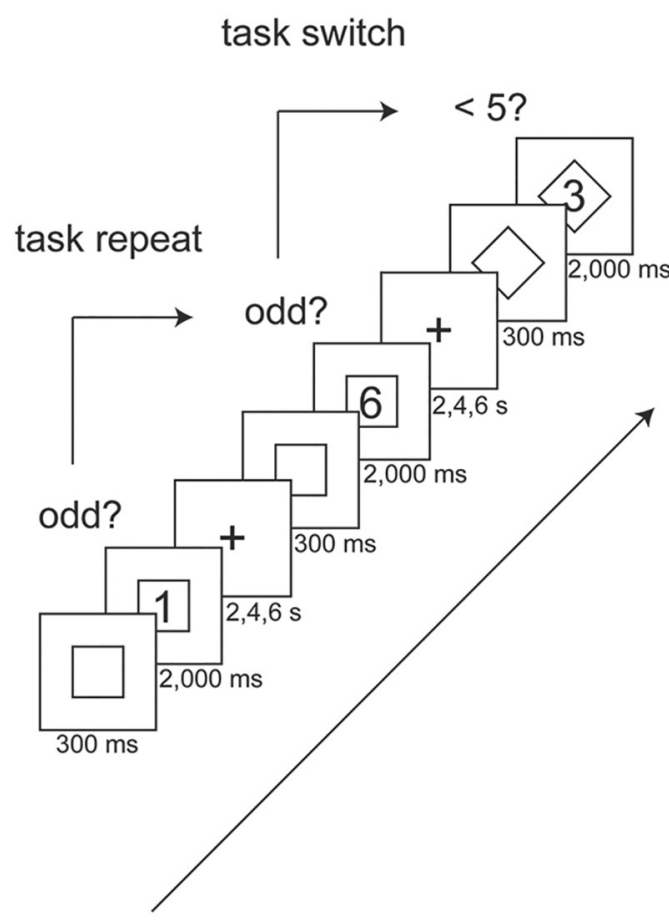

b

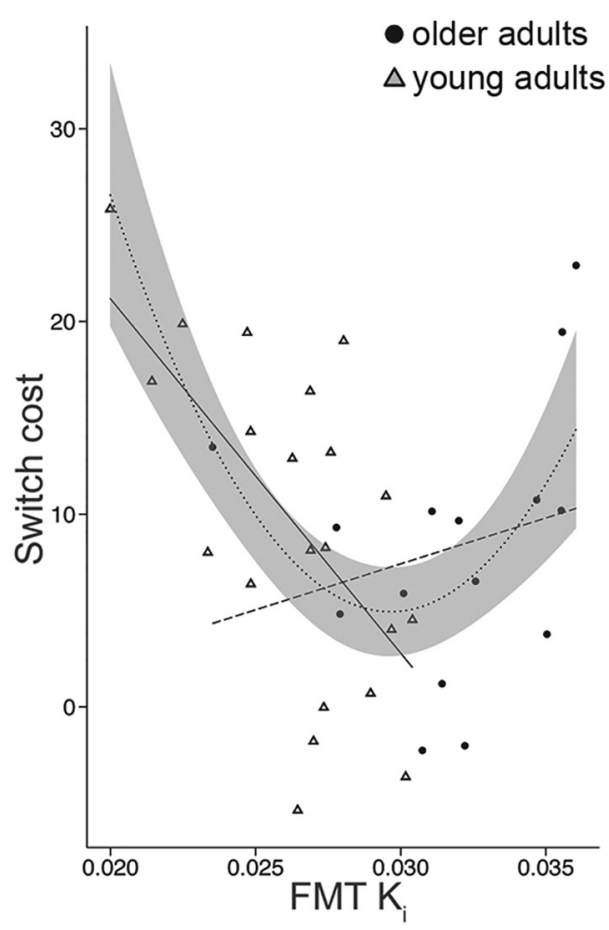

Figure 2. Relationship between FMT and switch cost. $\boldsymbol{a}$, Participants performed a two-condition task switching paradigm. Cues indicated whether the odd/even rule or the $>5 /<5$ rule applied. Switch cost was calculated as the percentage increase in response time for task switch trials relative to task repeat trials. $\boldsymbol{b}$, There was a U-shaped quadratic relationship between dorsal caudate FMT $\mathrm{K}_{\mathrm{i}}$ and switch cost $\left(r^{2}=0.36, p=0.0002 ; y=231,948.60 x^{2}-13,754.936 x+208.85\right)$. Dotted line indicates quadratic fit. Gray represents $90 \%$ confidence interval. There was a significant interaction between age group, FMT $K_{i}$, and switch $\operatorname{cost}\left(F_{(1,32)}=9.03, p=0.005\right)$. Solid line indicates young adult linear fit line. Dashed line indicates older adult linear fit line.

Analyses, including all activated regions, revealed no relationship between DCA FMT $K_{\mathrm{i}}$ and activation for the linear regression model $\left(F_{(1,34)}<1\right)$, but significant quadratic $\left(r^{2}=0.18\right.$, $\left.F_{(2,33)}=4.81, p=0.01\right)$ and cubic relationships $\left(r^{2}=0.15\right.$, $\left.F_{(3,32)}=3.11, p=0.04\right)$. Comparative testing across models confirmed the quadratic fit outperformed the linear $\left(F_{(1,33)}=8.51\right.$, $p=0.006)$, and cubic fit did not explain more variance than quadratic $\left(F_{(1,32)}<1\right)$. Permutation testing confirmed the stability of the quadratic effect ( $p=0.02 ; 1000$ permutations). ANOVA specifically testing the interaction of age group, DCA FMT $K_{\mathrm{i}}$, and activation indicated these relationships differed as a function of age group $\left(F_{(1,32)}=4.66, p=0.04\right)$, although the interaction did not remain significant after controlling for performance $\left(F_{(1,31)}=1.97, p=0.17\right)$. Young adults showed a correlation between DCA FMT $\mathrm{K}_{\mathrm{i}}$ and activation $(r=-0.47, p=$ 0.03 ), with no significant relationship at the higher synthesis levels in older adults $(r=0.22, p=0.43)$.

Analyses restricted to activation in lateral prefrontal and posterior parietal cortex showed a similar pattern of results. Follow-up analyses focused on these regions as they have been consistently implicated in task switching (Dove et al., 2000; Kimberg et al., 2000; Sohn et al., 2000). Activation extracted from ROIs ( $8 \mathrm{~mm}$ spheres) surrounding peaks in bilateral inferior frontal gyrus (MNI: 54, 6, 10; $-54,14,18$ ) and precuneus (MNI: $12,-68,52 ;-12,-68,48)$ was tested for age group differences, and was submitted to linear, quadratic, and cubic regression. There were no age-related differences in activation $\left(t_{(34)}<1\right)$. Additionally, there was not a significant linear relationship between activation and DCA FMT $\mathrm{K}_{\mathrm{i}}\left(r^{2}=0.001, F_{(1,34)}=1.04, p=\right.$ $0.31)$, although the quadratic $\left(r^{2}=0.28, F_{(2,33)}=7.76, p=\right.$ $0.002)$ and cubic relationships $\left(r^{2}=0.27, F_{(3,32)}=5.29\right.$, $p=0.004)$ were significant. Comparative testing across models confirmed the quadratic fit outperformed the linear $\left(F_{(1,33)}=\right.$ 14.07, $p<0.0007)$, and cubic fit did not explain more variance than quadratic $\left(F_{(1,32)}<1\right)$. Permutation testing confirmed the stability of the quadratic effect ( $p=0.001 ; 1000$ permutations). ANOVA specifically testing the interaction of age group, DCA FMT $\mathrm{K}_{\mathrm{i}}$, and activation indicated that these relationships differed as a function of age group $\left(F_{(1,32)}=8.53, p=0.006\right)$, which remained significant after controlling for performance $\left(F_{(1,31)}=\right.$ 5.62, $p=0.02$; Fig. $3 b$ ). Similar to effects reported above, young adults showed tight coupling between DCA FMT $\mathrm{K}_{\mathrm{i}}$ and activation $(r=-0.56, p=0.008)$, with no significant relationship at the higher synthesis levels in older adults $(r=0.32, p=0.24)$.

\section{Dopamine synthesis capacity and functional connectivity}

Task-relevant networks can be observed in the pattern of functional activity measured at rest (Fox et al., 2006). We investigated the influence of dopamine synthesis capacity on the strength of intrinsic functional connectivity within the corticostriatal networks thought to subserve cognitive flexibility. We generated frontoparietal functional connectivity maps using seeds defined from peak activation identified in the voxelwise analysis in lateral prefrontal and posterior parietal cortex (seeds from Fig. $3 b$, top, network in Fig. $5 a$ ), and measured the connectivity strength between this frontoparietal network and DCA.

Our findings were consistent with the patterns of effects observed for neural and behavioral measures of task switching. We found no age-related connectivity differences $\left(t_{(34)}<1\right)$. There was no linear relationship between DCA FMT $K_{\mathrm{i}}$ and connectivity $\left(F_{(1,34)}<1\right)$, although there were significant quadratic $\left(r^{2}=\right.$ $\left.0.16, F_{(2,33)}=4.44, p=0.02\right)$ and cubic $\left(r^{2}=0.15, F_{(3,32)}=3.10\right.$, 

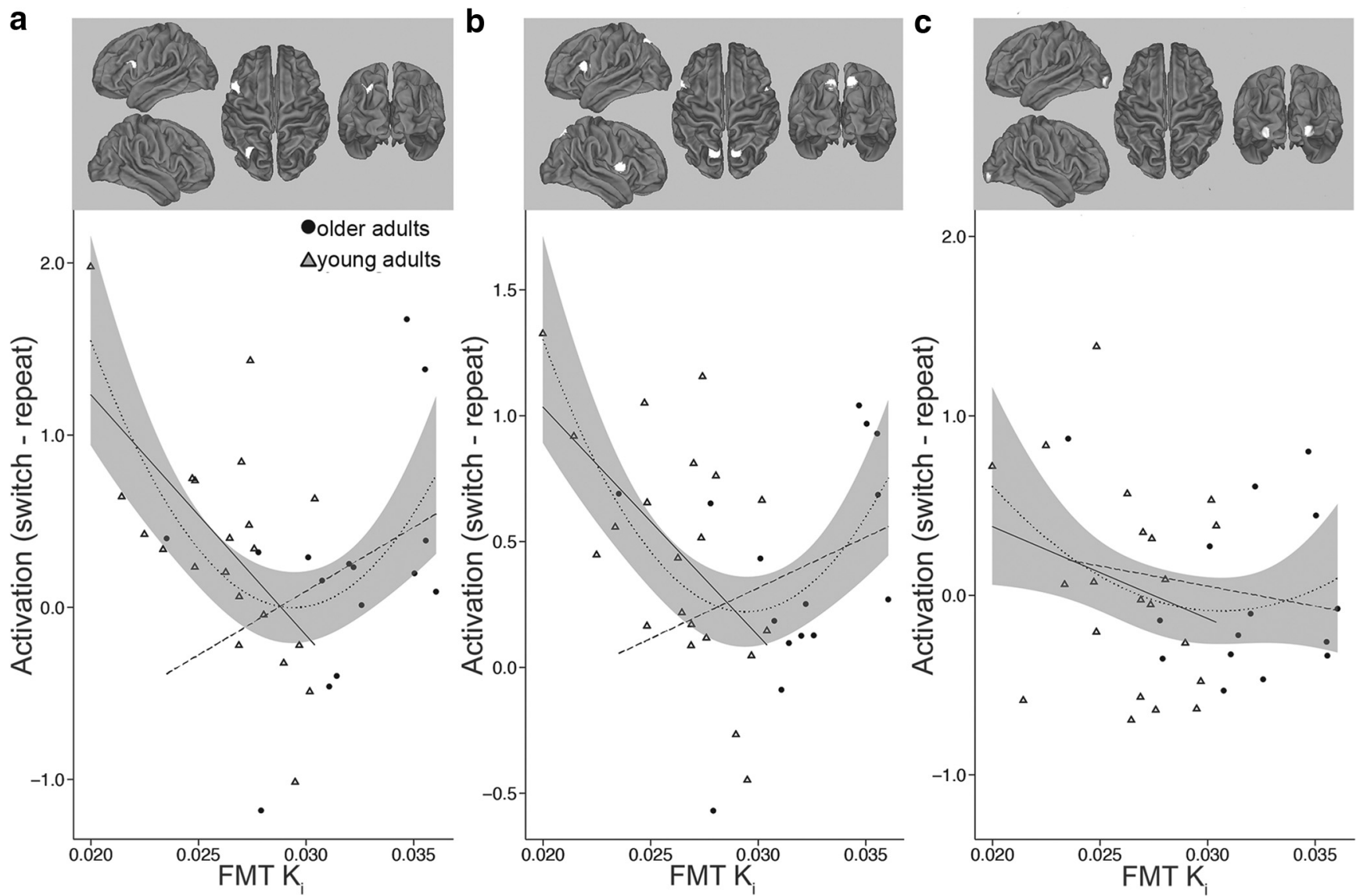

Figure 3. Relationship between FMT and frontoparietal activation. $\boldsymbol{a}$, There was a quadratic relationship between dorsal caudate FMT $\mathrm{K}_{\mathrm{i}}$ (average left and right) and frontoparietal activation in averaged a priori ROIs $\left(r^{2}=0.26, p=0.002 ; y=17477.89 x^{2}-1027.98 x+15.11\right) . a-c$, Dotted line indicates quadratic fit. Gray represents $90 \%$ confidence interval. There was a significant interaction between age group, FMT $K_{\mathrm{i}}$, and activation $\left(F_{(1,32)}=11.22, p=0.002\right)$. Solid line indicates young adult linear fit line. Dashed line indicates older adult linear fit line. R0ls were $8 \mathrm{~mm}$ spheres surrounding inferior frontal gyrus $(-46,14,24)$, and superior parietal lobule $(-28,-70,45)$ defined by Braver et al. (2003). $\boldsymbol{b}$, Similarly, there was a quadratic relationship between dorsal caudate FMT $K_{i}$ and averaged frontoparietal activation in ROIs defined by the present study $\left(r^{2}=0.28, p=0.002, y=12,153.36 x^{2}-715.18 x+10.74\right)$. There was a significant interaction between age group, FMT $K_{i}$, and activation $\left(F_{(1,32)}=8.53, p=0.006\right)$. ROls were $8 \mathrm{~mm}$ spheres surrounding bilateral inferior frontal gyrus $(54,6,10 ;-54,14,18)$ and precuneus $(12,-68,52$; $-12,-68,48)$. $c$, There was no quadratic relationship between dorsal caudate FMT $K_{\mathrm{i}}$ and primary visual cortex activation $\left(r^{2}=0.04, p=0.20\right)$, and no interaction between age group, FMT $K_{i}$, and activation $\left(F_{(1,32)}<1\right)$. ROls were $8 \mathrm{~mm}$ spheres surrounding primary visual cortex (MNI $\left.\pm 28,-96,-6\right)$. All coordinates are in MNI space.

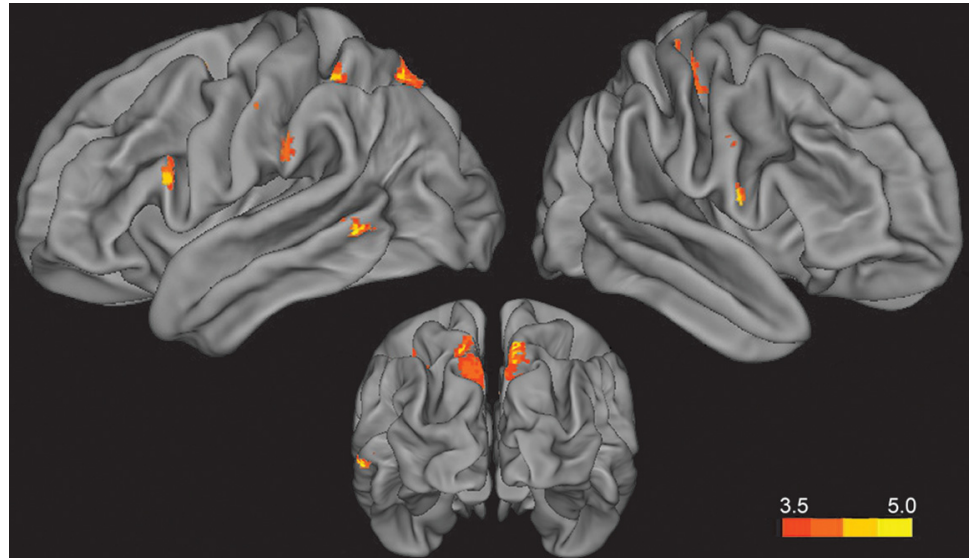

Figure 4. Univariate activation during task switching. Activation is displayed for the contrast switch $>$ repeat trials for young and older adults. T-maps are displayed on CARET semi-inflated templates with a combined height threshold of $p<0.001$ and 50 voxel extent threshold (AlphaSim cluster-level threshold, $p<0.05$ ). Scale reflects $t$ values.

$p=0.04)$ relationships. Data were best described by the invertedU-shaped quadratic function as tested against linear $\left(F_{(1,33)}=\right.$ $8.81, p=0.005)$ and cubic $\left(F_{(1,32)}<1\right)$ fits (Fig. $\left.5 b\right)$. Permutation testing confirmed the stability of the quadratic effect ( $p=0.004$;
1000 permutations). Examining groups independently, there was not an interaction with age group $\left(F_{(1,32)}=1.46\right.$, $p=0.24)$. Relationships between resting frontoparietal-DCA connectivity and dopamine were not significant (young $r=$ $0.26, p=0.26$; older $r=-0.16, p=57)$ possibly reflecting less consistent coupling with task-independent measures relative to task-related measures. There was, however, a modest correlation between connectivity and activation across both groups (all participants: $r=-0.38$, $p=0.02$ ), with stronger connectivity associated with smaller increases in frontoparietal activation during switch trials.

To confirm that our findings were specific to regions associated with cognitive flexibility, we measured the connectivity strength between the frontoparietal network and primary visual and motor cortex. We found a marginal age-related difference in connectivity with visual cortex $\left(t_{(34)}=1.73, p=0.09\right)$ with a trend for greater connectivity in older adults. Linear $\left(r^{2}=0.05, F_{(1,34)}=2.68, p=\right.$ 
Table 2. Results from the BOLD-fMRI analysis of the contrast switch > repeat

\begin{tabular}{|c|c|c|c|c|c|c|}
\hline \multirow[b]{2}{*}{ Anatomical label } & \multirow[b]{2}{*}{$\mathrm{BA}$} & \multicolumn{3}{|c|}{ MNI coordinates } & \multirow[b]{2}{*}{$t$ score } & \multirow{2}{*}{$\begin{array}{l}\text { Size } \\
\text { (voxels) }\end{array}$} \\
\hline & & $x$ & $y$ & $Z$ & & \\
\hline Inferior frontal/precentral gyrus & 44 & 54 & 6 & 10 & 5.31 & 105 \\
\hline Cingulate gyrus & 23 & 6 & -18 & 32 & 5.00 & 54 \\
\hline Precuneus & 7 & $\begin{array}{r}12 \\
-12\end{array}$ & $\begin{array}{l}-68 \\
-68\end{array}$ & $\begin{array}{l}52 \\
48\end{array}$ & $\begin{array}{l}4.97 \\
4.91\end{array}$ & 556 \\
\hline Middle temporal gyrus & 21 & -60 & -50 & 0 & 4.89 & 70 \\
\hline Postcentral gyrus & 2 & -62 & -24 & 26 & 4.75 & 101 \\
\hline Inferior parietal lobule & 40 & -36 & -42 & 54 & 4.66 & 222 \\
\hline Middle frontal gyrus & 6 & -28 & -8 & 58 & 4.57 & 86 \\
\hline Inferior frontal/precentral gyrus & 44 & -54 & 14 & 18 & 4.43 & 62 \\
\hline Precentral gyrus & 4 & 38 & -26 & 60 & 4.14 & 86 \\
\hline
\end{tabular}

$0.11)$, quadratic $\left(r^{2}=0.02, F_{(2,33)}=1.36, p=0.27\right)$, and cubic relationships $\left(F_{(3,32)}<1\right)$ with DCA FMT K $\mathrm{K}_{\mathrm{i}}$ were not significant, and there was no age group $\times$ DCA FMT Ki $\times$ connectivity interaction $\left(F_{(1,32)}<1\right)$ (Fig. $\left.5 c\right)$. Similarly, for motor cortex, we found no age-related difference in connectivity $\left(t_{(34)}<1\right)$. Linear, quadratic, and cubic relationships were not significant (all $F$ values $\leq 1)$, and there was no age group $\times$ DCA FMT Ki $\times$ connectivity interaction $\left(F_{(1,32)}<1\right)$.

\section{Discussion}

We show that striatal dopamine synthesis capacity (PET FMT $\mathrm{K}_{\mathrm{i}}$ ) is elevated in healthy older adults relative to young. Although higher levels of dopamine synthesis capacity appeared to benefit cognitive flexibility in young adults, these relationships were altered in older adults as evidenced by interactions between age, dopamine, and task switching measures. Our findings contribute to a growing body of research associating age-related differences in endogenous dopamine markers with cognition. To date, the majority of studies have focused on the detrimental effect of decreases in postsynaptic measures of $\mathrm{D}_{1}$ (Wang et al., 1998) and $\mathrm{D}_{2}$ receptor density (Volkow et al., 1998; Bäckman et al., 2000) as well as presynaptic measures of the dopamine transporter (Mozley et al., 2001; Erixon-Lindroth et al., 2005) on cognition. Our findings offer a new perspective on how dopamine synthesis is related to cognitive flexibility, and how these mechanisms underlie variability in cognition.

Although there has been clear demonstration of decreases in receptor and transporter density (Seeman et al., 1987; Volkow et al., 1994; Frey et al., 1996; Ishibashi et al., 2009) underlying cognitive decline in aging (Bäckman et al., 2000; Erixon-Lindroth et al., 2005; Bäckman et al., 2011), there is accumulating evidence

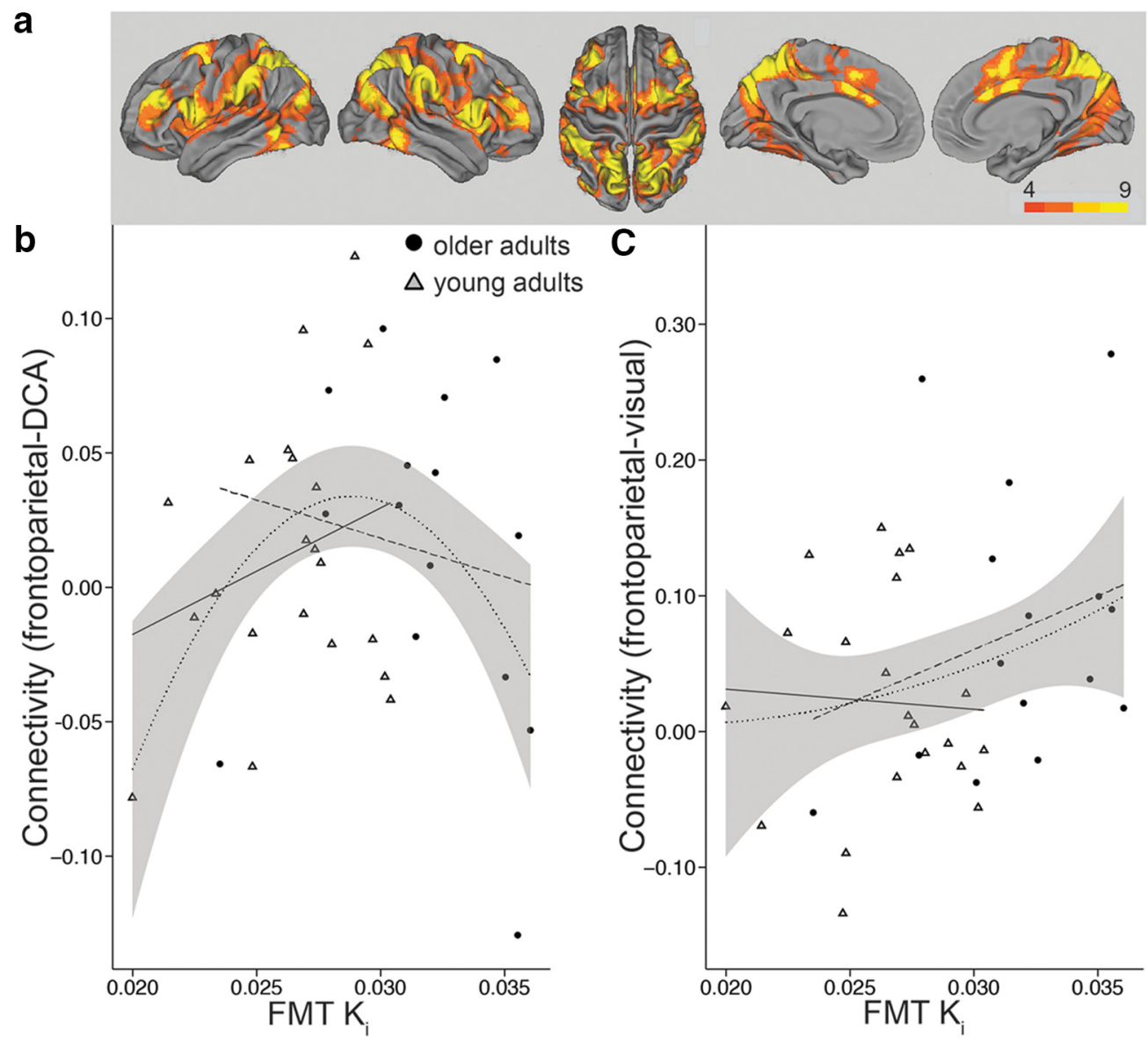

Figure 5. Relationship between FMT and frontoparietal-dorsal caudate functional connectivity. $\boldsymbol{a}$, Frontoparietal resting state functional connectivity maps were generated using seeds identified in the univariate analysis for the contrast switch $>$ repeat. Seeds were $8 \mathrm{~mm}$ spheres surrounding bilateral inferior frontal gyrus $(54,6,10 ;-54,14,18)$ and precuneus $(12,-68,52 ;-12,-68$, 48). T-maps are displayed on CARET semi-inflated templates. Scale reflects $t$ values. Coordinates are in MNI space. $\boldsymbol{b}$, There was a quadratic relationship between dorsal caudate FMT $K_{i}$ (average left and right) and frontoparietal-DCA functional connectivity $\left(r^{2}=0.16, p=0.02, y=-1295.57 x^{2}+74.75-1.04\right)$. There was not a significant interaction between age group, FMT $\mathrm{K}_{\mathrm{i}}$, and connectivity $\left(F_{(1,32)}=1.46, p=0.24\right)$. $\boldsymbol{b}, \boldsymbol{c}$, Dotted line indicates quadratic fit. Gray represents $90 \%$ confidence interval. Solid line indicates young adult linear fit line. Dashed line indicates older adult linear fit line. $c$, There was no quadratic relationship between dorsal caudate FMT $\mathrm{K}_{\mathrm{i}}$ and frontoparietal-primary visual cortex functional connectivity $\left(r^{2}=0.02, p=0.27\right)$, and no interaction between age group, FMT $\mathrm{K}_{\mathrm{i}}$, and functional connectivity $\left(F_{(1,32)}<1\right)$. 
supporting upregulation of dopamine synthesis (Kish et al., 1995; Lee et al., 2000; Braskie et al., 2008; Nandhagopal et al., 2011), which could serve a compensatory function. Despite limited sample size, the present study replicates previous results demonstrating elevated FMT $\mathrm{K}_{\mathrm{i}}$ in healthy older adults relative to young (Braskie et al., 2008). Importantly, a multimodal approach allowed us to assess age-related differences in dopamine function independent of changes involving amyloid deposition. While findings using FDOPA, another tracer targeting aromatic amino acid decarboxylase, have been mixed (Martin et al., 1989; Sawle et al., 1990; Bhatt et al., 1991; Wolf et al., 1991; Dreher et al., 2008), methodological considerations may contribute to inconsistencies. For example, FDOPA's affinity is 10 -fold weaker than FMT's and is affected at longer scan times (Sossi et al., 2002), by vesicular uptake, synaptic release, and metabolism, decreasing signal-to-noise.

Our findings reveal strong links between DCA dopamine and cognitive flexibility and define the neural mechanisms of its influence in young adults. Specifically, higher synthesis capacity was associated with lower switch costs and smaller activation increases during switch trials, suggesting that frontoparietal efficiency underlies enhanced performance (Stelzel et al., 2010). These findings were consistent for a priori regions selected based on their transient response during switch trials (Braver et al., 2003), as well as for exploratory analyses. Neocortical activation has been previously linked to striatal measures of dopamine synthesis capacity (Landau et al., 2009; Dang et al., 2012; Deserno et al., 2015) and $\mathrm{D}_{1}$ (Bäckman et al., 2011) and $\mathrm{D}_{2}$ receptor binding (Nyberg et al., 2009). The influence of dopamine signaling in DCA on frontoparietal cortex is likely mediated by parallel cortico-striato-thalamo-cortical loops (Alexander et al., 1986). Transient activation of this circuitry may allow for a release in thalamic gating, enabling updating of representations held in cortex (Frank et al., 2001) in support of task switching.

Across groups, we found that relationships between DCA dopamine and cognitive flexibility measures were best described by quadratic, U-shaped regression models. These findings suggest that optimal cognitive flexibility is achieved only at midrange levels of dopamine synthesis. However, scrutiny of dopamine relationships within group revealed nonsignificant correlations between dopamine and cognitive flexibility measures for older adults. Although the interpretation of the within-group null effects is not entirely clear in view of the limited sample size, they temper the interpretation that elevated synthesis capacity in aging is detrimental. What is clear, however, is that age-related increases in dopamine synthesis capacity are associated with altered dopamine-cognition relationships. Supporting our findings, similar interactions with age and dopamine synthesis capacity have been demonstrated for prefrontal cortex activation during reward anticipation and outcome (Dreher et al., 2008).

Resting functional connectivity findings point to modulation of network tuning as a possible mechanism by which dopamine affects performance and frontoparietal activation. DCA dopamine's quadratic fit with frontoparietal-DCA connectivity suggested stronger connectivity strength for midrange synthesis values, although strong interpretation of these effects warrants caution as the correlation between synthesis capacity and connectivity strength was not significant for young adults. However, this proposed mechanism is in agreement with previous demonstrations in young adults that dopamine depletion regimens weaken functional connectivity in these networks (Nagano-Saito et al., 2008), likely making their successful recruitment more ef- fortful during task performance. Further support is established in the present dataset by the correlation between connectivity strength and activation such that greater connectivity was associated with smaller activation increases for switch trials.

Future studies must try to resolve the mechanisms underlying the changes in dopamine-cognition relationships with age. Key questions remain regarding the relationship between elevated dopamine synthesis capacity in aging and the loss of receptors, transporters, and gray matter volume. PET studies of Parkinson's disease suggest there are compensatory increases in dopamine synthesis, but that increases are small and are quickly outpaced by losses incurred during disease progression (Lee et al., 2000; Nandhagopal et al., 2011). In the present study, it is possible that most elevated dopamine synthesis capacity tracks advanced dysfunction in the system. Any compensatory benefit of elevated dopamine synthesis for older adults may have provided a boost to performance and neural measures that precluded a pure reversal of effects observed in young adults. Pharmacological studies may explore this possibility by resolving whether dopamine depletion impairs flexible performance in older adults with highest synthesis values, or, alternatively, whether it improves performance. While the present study defined clear relationships between striatal dopamine and cognitive flexibility in young adults, the complexity of the relationships between age, presynaptic and postsynaptic dopamine measures, and brain activity will require further investigation using integrated neuroscience approaches to disentangle.

\section{References}

Alexander GE, DeLong MR, Strick PL (1986) Parallel organization of functionally segregated circuits linking basal ganglia and cortex. Annu Rev Neurosci 9:357-381. CrossRef Medline

Anderson JS, Ferguson MA, Lopez-Larson M, Yurgelun-Todd D (2011) Reproducibility of single-subject functional connectivity measurements. AJNR Am J Neuroradiol 32:548-555.

Bäckman L, Ginovart N, Dixon RA, Wahlin TB, Wahlin A, Halldin C, Farde L (2000) Age-related cognitive deficits mediated by changes in the striatal dopamine system. Am J Psychiatry 157:635-637. CrossRef Medline

Bäckman L, Karlsson S, Fischer H, Karlsson P, Brehmer Y, Rieckmann A, MacDonald SW, Farde L, Nyberg L (2011) Dopamine D(1) receptors and age differences in brain activation during working memory. Neurobiol Aging 32:1849-1856. CrossRef Medline

Bakeman R (2005) Recommended effect size statistics for repeated measures designs. Behav Res Methods 37:379-384. CrossRef Medline

Bentler PM, Kano Y (1990) On the equivalence of factors and components. Multivariate Behav Res 25:67-74. CrossRef Medline

Bhatt MH, Snow BJ, Martin WR, Pate BD, Ruth TJ, Calne DB (1991) Positron emission tomography suggests that the rate of progression of idiopathic parkinsonism is slow. Ann Neurol 29:673-677. CrossRef Medline

Braskie MN, Wilcox CE, Landau SM, O’Neil JP, Baker SL, Madison CM, Kluth JT, Jagust WJ (2008) Relationship of striatal dopamine synthesis capacity to age and cognition. J Neurosci 28:14320-14328. CrossRef Medline

Braver TS, Reynolds JR, Donaldson DI (2003) Neural mechanisms of transient and sustained cognitive control during task switching. Neuron 39: 713-726. CrossRef Medline

Cools R, D’Esposito M (2011) Inverted-U-shaped dopamine actions on human working memory and cognitive control. Biol Psychiatry 69:e113e125. CrossRef Medline

Cools R, Robbins TW (2004) Chemistry of the adaptive mind. Philos Trans A Math Phys Eng Sci 362:2871-2888. CrossRef Medline

Cools R, Gibbs SE, Miyakawa A, Jagust W, D’Esposito M (2008) Working memory capacity predicts dopamine synthesis capacity in the human striatum. J Neurosci 28:1208-1212. CrossRef Medline

Daneman M, Carpenter PA (1980) Individual differences in working memory and reading. J Verb Learn Verb Be 19:450-466. CrossRef

Dang LC, Donde A, Madison C, O’Neil JP, Jagust WJ (2012) Striatal dopa- 
mine influences the default mode network to affect shifting between object features. J Cogn Neurosci 24:1960-1970. CrossRef Medline

DeJesus OT (2003) Positron-labeled DOPA analogs to image dopamine terminals. Drug Dev Res 59:249-260. CrossRef

DeJesus OT, Endres CJ, Shelton SE, Nickles RJ, Holden JE (2001) Noninvasive assessment of aromatic L-amino acid decarboxylase activity in aging rhesus monkey brain in vivo. Synapse 39:58-63. CrossRef Medline

Delis DC, Kramer JH, Kaplan E, Ober BA (2000) California Verbal Learning Test, Ed 2. San Antonio: Psychological Corporation.

Deserno L, Huys QJ, Boehme R, Buchert R, Heinze HJ, Grace AA, Dolan RJ, Heinz A, Schlagenhauf F (2015) Ventral striatal dopamine reflects behavioral and neural signatures of model-based control during sequential decision making. Proc Natl Acad Sci U S A 112:1595-1600. CrossRef Medline

Dove A, Pollmann S, Schubert T, Wiggins CJ, von Cramon DY (2000) Prefrontal cortex activation in task switching: an event-related fMRI study. Brain Res Cogn Brain Res 9:103-109. CrossRef Medline

Dreher JC, Meyer-Lindenberg A, Kohn P, Berman KF (2008) Age-related changes in midbrain dopaminergic regulation of the human reward system. Proc Natl Acad Sci U S A 105:15106-15111. CrossRef Medline

Eklund A, Nichols TE, Knutsson H (2016) Cluster failure: why fMRI inferences for spatial extent have inflated false-positive rates. Proc Natl Acad Sci U S A 113:7900-7905. CrossRef Medline

Erixon-Lindroth N, Farde L, Wahlin TB, Sovago J, Halldin C, Bäckman L (2005) The role of the striatal dopamine transporter in cognitive aging. Psychiatry Res 138:1-12. CrossRef Medline

Fearnley JM, Lees AJ (1991) Ageing and Parkinson's disease: substantia nigra regional selectivity. Brain 114:2283-2301. CrossRef Medline

Folstein MF, Folstein SE, McHugh PR (1975) "Mini-mental state": a practical method for grading the cognitive state of patients for the clinician. J Psychiatr Res 12:189-198. CrossRef Medline

Fox MD, Corbetta M, Snyder AZ, Vincent JL, Raichle ME (2006) Spontaneous neuronal activity distinguishes human dorsal and ventral attention systems. Proc Natl Acad Sci U S A 103:10046-10051. CrossRef Medline

Frank MJ, Loughry B, O'Reilly RC (2001) Interactions between frontal cortex and basal ganglia in working memory: a computational model. Cogn Affect Behav Neurosci 1:137-160. CrossRef Medline

Frey KA, Koeppe RA, Kilbourn MR, Vander Borght TM, Albin RL, Gilman S, Kuhl DE (1996) Presynaptic monoaminergic vesicles in Parkinson's disease and normal aging. Ann Neurol 40:873-884. CrossRef Medline

Friston KJ, Frith CD, Turner R, Frackowiak RS (1995) Characterizing evoked hemodynamics with fMRI. Neuroimage 2:157-165. CrossRef Medline

Friston KJ, Ashburner JT, Kiebel SJ, Nichols TE, Penny WD (2011) Parametric mapping: the analysis of functional brain images: San Diego: Academic.

Fritz CO, Morris PE, Richler JJ (2012) Effect size estimates: current use, calculations, and interpretation. J Exp Psychol Gen 141:2-18. CrossRef Medline

Grinband J, Wager TD, Lindquist M, Ferrera VP, Hirsch J (2008) Detection of time-varying signals in event-related fMRI designs. Neuroimage 43: 509-520. CrossRef Medline

Ishibashi K, Ishii K, Oda K, Kawasaki K, Mizusawa H, Ishiwata K (2009) Regional analysis of age-related decline in dopamine transporters and dopamine D2-like receptors in human striatum. Synapse 63:282-290. CrossRef Medline

Jimura K, Braver TS (2010) Age-related shifts in brain activity dynamics during task switching. Cereb Cortex 20:1420-1431. CrossRef Medline

Kimberg DY, Aguirre GK, D’Esposito M (2000) Modulation of task-related neural activity in task-switching: an fMRI study. Brain Res Cogn Brain Res 10:189-196. CrossRef Medline

Kish SJ, Zhong XH, Hornykiewicz O, Haycock JW (1995) Striatal 3,4dihydroxyphenylalanine decarboxylase in aging: disparity between postmortem and positron emission tomography studies? Ann Neurol 38: 260-264. CrossRef Medline

Kiviniemi V, Starck T, Remes J, Long X, Nikkinen J, Haapea M, Veijola J, Moilanen I, Isohanni M, Zang YF, Tervonen O (2009) Functional segmentation of the brain cortex using high model order group PICA. Hum Brain Mapp 30:3865-3886. CrossRef Medline

Klanker M, Feenstra M, Denys D (2013) Dopaminergic control of cognitive flexibility in humans and animals. Front Neurosci 7:201. CrossRef Medline
Klostermann EC, Braskie MN, Landau SM, O’Neil JP, Jagust WJ (2012) Dopamine and frontostriatal networks in cognitive aging. Neurobiol Aging 623:e15-e24. CrossRef Medline

Landau SM, Lal R, O’Neil JP, Baker S, Jagust WJ (2009) Striatal dopamine and working memory. Cereb Cortex 19:445-454. CrossRef Medline

Lee CS, Samii A, Sossi V, Ruth TJ, Schulzer M, Holden JE, Wudel J, Pal PK, de la Fuente-Fernandez R, Calne DB, Stoessl AJ (2000) In vivo positron emission tomographic evidence for compensatory changes in presynaptic dopaminergic nerve terminals in Parkinson's disease. Ann Neurol 47: 493-503. CrossRef Medline

Martin WR, Palmer MR, Patlak CS, Calne DB (1989) Nigrostriatal function in humans studied with positron emission tomography. Ann Neurol 26: 535-542. CrossRef Medline

Mawlawi O, Martinez D, Slifstein M, Broft A, Chatterjee R, Hwang DR, Huang Y, Simpson N, Ngo K, Van Heertum R, Laruelle M (2001) Imaging human mesolimbic dopamine transmission with positron emission tomography: I. Accuracy and precision of $\mathrm{D}(2)$ receptor parameter measurements in ventral striatum. J Cereb Blood Flow Metab 21:1034-1057. CrossRef Medline

Mayka MA, Corcos DM, Leurgans SE, Vaillancourt DE (2006) Threedimensional locations and boundaries of motor and premotor cortices as defined by functional brain imaging: a meta-analysis. Neuroimage 31 : 1453-1474. CrossRef Medline

Meiran N, Chorev Z, Sapir A (2000) Component processes in task switching. Cogn Psychol 41:211-253. CrossRef Medline

Mozley LH, Gur RC, Mozley PD, Gur RE (2001) Striatal dopamine transporters and cognitive functioning in healthy men and women. Am J Psychiatry 158:1492-1499. CrossRef Medline

Nagano-Saito A, Leyton M, Monchi O, Goldberg YK, He Y, Dagher A (2008) Dopamine depletion impairs frontostriatal functional connectivity during a set-shifting task. J Neurosci 28:3697-3706. CrossRef Medline

Nandhagopal R, Kuramoto L, Schulzer M, Mak E, Cragg J, McKenzie J, McCormick S, Ruth TJ, Sossi V, de la Fuente-Fernandez R, Stoessl AJ (2011) Longitudinal evolution of compensatory changes in striatal dopamine processing in Parkinson's disease. Brain 134:3290-3298. CrossRef Medline

Nyberg L, Andersson M, Forsgren L, Jakobsson-Mo S, Larsson A, Marklund P, Nilsson LG, Riklund K, Bäckman L (2009) Striatal dopamine D2 binding is related to frontal BOLD response during updating of long-term memory representations. Neuroimage 46:1194-1199. CrossRef Medline

Patlak CS, Blasberg RG (1985) Graphical evaluation of blood-to-brain transfer constants from multiple-time uptake data. Generalizations. J Cereb Blood Flow Metab 5:584-590. CrossRef Medline

Peirce JW (2007) PsychoPy-Psychophysics software in Python. J Neurosci Methods 162:8-13. CrossRef Medline

Reitan RM, Wolfson D (1985) The Halstead-Reitan Neuropsychological Test Battery: theory and clinical interpretation. Tucson, AZ: Neuropsychological.

Rousset OG, Ma Y, Evans AC (1998) Correction for partial volume effects in PET: principle and validation. J Nucl Med 39:904-911. Medline

Samanez-Larkin GR, Buckholtz JW, Cowan RL, Woodward ND, Li R, Ansari MS, Arrington CM, Baldwin RM, Smith CE, Treadway MT, Kessler RM, Zald DH (2013) A thalamocorticostriatal dopamine network for psychostimulant-enhanced human cognitive flexibility. Biol Psychiatry 74:99-105. CrossRef Medline

Sawle GV, Colebatch JG, Shah A, Brooks DJ, Marsden CD, Frackowiak RS (1990) Striatal function in normal aging: implications for Parkinson's disease. Ann Neurol 28:799-804. CrossRef Medline

Schöll M, Lockhart SN, Schonhaut DR, O’Neil JP, Janabi M, Ossenkoppele R, Baker SL, Vogel JW, Faria J, Schwimmer HD, Rabinovici GD, Jagust WJ (2016) PET imaging of tau deposition in the aging human brain. Neuron 89:971-982. CrossRef Medline

Seeman P, Bzowej NH, Guan HC, Bergeron C, Becker LE, Reynolds GP, Bird ED, Riederer P, Jellinger K, Watanabe S (1987) Human brain dopamine receptors in children and aging adults. Synapse 1:399-404. CrossRef Medline

Smith A (1982) Symbol Digit Modalities Test: manual. Los Angeles: Western Psychological Services.

Sohn MH, Ursu S, Anderson JR, Stenger VA, Carter CS (2000) The role of prefrontal cortex and posterior parietal cortex in task switching. Proc Natl Acad Sci U S A 97:13448-13453. CrossRef Medline

Song XW, Dong ZY, Long XY, Li SF, Zuo XN, Zhu CZ, He Y, Yan CG, Zang 
YF (2011) REST: a toolkit for resting-state functional magnetic resonance imaging data processing. PLoS One 6:e25031. CrossRef Medline

Sossi V, de La Fuente-Fernández R, Holden JE, Doudet DJ, McKenzie J, Stoessl AJ, Ruth TJ (2002) Increase in dopamine turnover occurs early in Parkinson's disease: evidence from a new modeling approach to PET 18 F-fluorodopa data. J Cereb Blood Flow Metab 22:232-239. CrossRef Medline

Spreen O, Benton LA (1977) Neurosensory Center Comprehensive Examination for Aphasia: manual of directions. New York: Springer.

Stelzel C, Basten U, Montag C, Reuter M, Fiebach CJ (2010) Frontostriatal involvement in task switching depends on genetic differences in $\mathrm{d} 2$ receptor density. J Neurosci 30:14205-14212. CrossRef Medline

Stroop JR (1938) Factors affecting speed in serial verbal reactions. Psychol Monogr 50:38-48. CrossRef

VanBrocklin HF, Blagoev M, Hoepping A, O’Neil JP, Klose M, Schubiger PA, Ametamey S (2004) A new precursor for the preparation of 6-[18F]fluoro-L-m-tyrosine ([18F]FMT): efficient synthesis and comparison of radiolabeling. Appl Radiat Isot 61:1289-1294. CrossRef Medline

Villeneuve S, Rabinovici GD, Cohn-Sheehy BI, Madison C, Ayakta N, Ghosh PM, La Joie R, Arthur-Bentil SK, Vogel JW, Marks SM, Lehmann M, Rosen HJ, Reed B, Olichney J, Boxer AL, Miller BL, Borys E, Jin LW, Huang EJ, Grinberg LT, et al. (2015) Existing Pittsburgh Compound-B positron emission tomography thresholds are too high: statistical and pathological evaluation. Brain 138:2020-2033. CrossRef Medline

Volkow ND, Fowler JS, Wang GJ, Logan J, Schlyer D, MacGregor R, Hitzemann R, Wolf AP (1994) Decreased dopamine transporters with age in health human subjects. Ann Neurol 36:237-239. CrossRef Medline

Volkow ND, Gur RC, Wang GJ, Fowler JS, Moberg PJ, Ding YS, Hitzemann R,
Smith G, Logan J (1998) Association between decline in brain dopamine activity with age and cognitive and motor impairment in healthy individuals. Am J Psychiatry 155:344-349. CrossRef Medline

Wang Y, Chan GL, Holden JE, Dobko T, Mak E, Schulzer M, Huser JM, Snow BJ, Ruth TJ, Calne DB, Stoessl AJ (1998) Age-dependent decline of dopamine D1 receptors in human brain: a PET study. Synapse 30:56-61. CrossRef Medline

Wasylyshyn C, Verhaeghen P, Sliwinski MJ (2011) Aging and task switching: a meta-analysis. Psychol Aging 26:15-20. CrossRef Medline

Wechsler D (1987) Wechsler Memory Scale, revised, manual. San Antonio: Psychological Corporation.

Whitfield-Gabrieli S, Nieto-Castanon A (2012) Conn: a functional connectivity toolbox for correlated and anticorrelated brain networks. Brain Connect 2:125-141. CrossRef Medline

Wolf ME, LeWitt PA, Bannon MJ, Dragovic LJ, Kapatos G (1991) Effect of aging on tyrosine hydroxylase protein content and the relative number of dopamine nerve terminals in human caudate. J Neurochem 56:11911200. CrossRef Medline

Woo CW, Krishnan A, Wager TD (2014) Cluster-extent based thresholding in fMRI analyses: pitfalls and recommendations. Neuroimage 91:412419. CrossRef Medline

Yarkoni T, Barch DM, Gray JR, Conturo TE, Braver TS (2009) BOLD correlates of trial-by-trial reaction time variability in gray and white matter: a multi-study fMRI analysis. PLoS One 4:e4257. CrossRef Medline

Yesavage JA, Brink TL, Rose TL, Lum O, Huang V, Adey M, Leirer VO (1982) Development and validation of a geriatric depression screening scale: a preliminary report. J Psychiatr Res 17:37-49. CrossRef Medline 